TITLE:

\title{
Fruiting and flushing phenology in Asian tropical and temperate forests: implications for primate ecology.
}

$\operatorname{AUTHOR}(\mathrm{S})$ :

Hanya, Goro; Tsuji, Yamato; Grueter, Cyril C

\section{CITATION:}

Hanya, Goro ... [et al]. Fruiting and flushing phenology in Asian tropical and temperate forests: implications for primate ecology.. Primates 2013, 54(2): 101-110

\section{ISSUE DATE:}

2013-04

URL:

http://hdl.handle.net/2433/173355

\section{RIGHT:}

The final publication is available at www.springerlink.com; この論文は 著者最終稿です。内容が印刷版と異なることがありますので、引用の 際には出版社版をご確認ご利用ください。This is the Accepted Author Manuscript. Please cite only the published version. 
1 Fruiting and flushing phenology in Asian tropical and temperate forests:

2 implications for primate ecology

3

4 Goro Hanya ${ }^{1}$, Yamato Tsuji ${ }^{1}$ and Cyril C. Grueter $^{2}$

5

$6{ }^{1}$ Primate Research Institute, Kyoto University, Japan

$7 \quad{ }^{2}$ School of Anatomy, Physiology and Human Biology, The University of Western

8 Australia, Australia

9

10 Correspondence to: G. Hanya: Primate Research Institute, Kyoto University,

11 Kanrin 41-2, Inuyama, Aichi, 484-8506 Japan. E-mail: hanya@pri.kyoto-u.ac.jp,

12 Tel: +81-568-63-0542, Fax: +81-568-63-0564

13

14 Running title: Fruiting and flushing phenology

15

16 This manuscript is submitted for the special issue of 'Out of the tropics: Ecology

17 of temperate primates'

18 
19 Abstract

20 In order to understand the ecological adaptations of primates to survive in

21 temperate forests, we need to know the general patterns of plant phenology in

22 temperate and tropical forests. Comparative analyses have been employed to

23 investigate general trends in the seasonality and abundance of fruit and young

24 leaves in tropical and temperate forests. Previous studies have shown that 1)

25 fruit fall biomass in temperate forest is lower than in tropical forest, 2) non-fleshy

26 species, in particular acorns, comprise the majority of the fruit biomass in

27 temperate forest, 3 ) the duration of fruiting season is shorter in temperate forest, and 4) in most temperate forests the fruiting peak occurs in autumn. Through our comparative analyses on the fruiting and flushing phenology between Asian temperate and tropical forests, we revealed that 1) fruiting is more annually periodic (the pattern in one year is similar to the one in the next year) in temperate forest in terms of the number of fruiting species or trees, 2) there is no consistent difference in inter-annual variations in fruiting between temperate and tropical forests, although some oak-dominated temperate forests exhibited extremely large inter-annual variations in fruiting, 3) the timing of the flushing peak is predictable (in spring and early summer) and 4) the duration of the flushing season is shorter. The flushing season in temperate forests $(17-28 \%$ of that in tropical forests) was quite limited, even compared to the fruiting season (68\%). These results imply that temperate primates need to survive a long period of scarcity of the young leaves and fruits, but the timing is predictable.

41 Therefore, dependence on low-quality foods would be indispensable for

42 temperate primates, such as mature leaves, buds, bark and lichens. Due to the 43 high predictability of the timing of fruiting and flushing in temperate forests, fat 
44 accumulation during the fruit-abundant period and fat metabolization during the

45 subsequent fruit-scarce period can be an effective strategy to survive the lean 46 period (winter).

47 Keywords: fruit, primates, temperate forest, tropical forest, young leaf 48 
Introduction

Latitude exerts a strong influence on various ecological phenomena: increased species diversity at higher compared to lower latitudes (Eeley and Lawes 1999; Badgley and Fox 2000; Stevens and Willig 2002; Hillebrand 2004; Takyu et al. 2005) and variation in animals' dietary strategies (Nakagawa et al. 1996; Zhou et al. 2011) are well-known examples. Since primates are distributed over a large latitudinal range, from $34^{\circ} \mathrm{S}$ to $41^{\circ} \mathrm{N}$ (Fleagle 1999), it is important to clarify the latitudinal cline in their habitat to understand the variability with their ecology. As a driving force behind the latitudinal cline of primates' ecological characteristics, climate is sometimes cited, e.g. through its effect on thermoregulation (Iwamoto and Dunbar 1983; Hanya et al. 2007). However, biotic factors, such as food, are often direct causes. For example, within the Japanese archipelago, the availability of mature leaves in winter changes with latitude, and this significantly affects food quality (Nakagawa et al. 1996) and, in turn, the population density of Japanese macaques (Takasaki 1981; Hanya et al. 2006).

In order to understand the ecology of generalist primary consumers, such as primates, data on forest productivity are indispensable. Moreover, since the essential difference between the temperate and tropical regions lies in seasonality (Martyn 1992), comparisons of plant phenology are particularly important. Global patterns of the variations in plant phenology have typically been discussed separately for tropical and temperate regions (van Schaik et al. 1993; Lechowicz 1995; van Schaik and Pfannes 2005). However, a direct comparison of habitat characteristics is needed in order to clarify the selective pressure imposed on animals that had radiated from tropical to temperate 
74 regions or vice versa. Primates in temperate regions are particularly interesting

75 for this purpose: they had originated in the tropics and lack special physiological

76 adaptations, such as hibernation, to survive in the cold winter (Fleagle 1999).

77 They eat a wide variety of foods, including the reproductive and vegetative parts

78 of plants as well as animal matter (Clutton-Brock 1977; Hohmann et al. 2006).

79 Therefore, temperate primates need to cope with a stronger seasonality of

80 various foods compared to that in the tropics.

$81 \quad$ Recently, progress has been made in the comparison between tropical

82 and temperate forests with regard to their characteristics as habitats for

83 consumers. In particular, patterns in fruit availability have largely been clarified,

84 at least those patterns occurring in a single year. Here, we summarize the

85 findings of these comparative studies. First, fruit production is generally larger

86 in tropical than in temperate forest, but there is a huge overlap between the two

87 regions (Hanya and Aiba 2010b). Based on a review of 51 temperate and

88 tropical forests throughout the world, Hanya and Aiba (2010b) found that fruit fall

89 in the tropical forests (average \pm SD: $454 \pm 258 \mathrm{~kg} / \mathrm{ha} /$ year, range: $32-1165$ ) is,

90 on average, 1.71 times larger than that in the temperate forests $(265 \pm 227$,

91 excluding Australia, range: 10-595). Although mean fruit fall is different

92 between the two regions, the ranges considerably overlap. For example, the

93 highest fruit fall in a temperate region (lowland forest in Yakushima, Japan) is

94 between the $6^{\text {th }}$ and $7^{\text {th }}$ highest levels among the 25 tropical sites.

Second, in temperate forests, the duration of the fruiting season is

96 shorter, but its peak is more predictable than in tropical forests. Using the data

97 taken from 48 sites in a single year, Ting et al. (2008) revealed that the duration

98 of the fruiting season (assessed by the circular standard deviation, see Method 
99 for our comparative analysis of flushing) decreases with increasing absolute

100 latitude. When regressed on a Gaussian curve, the duration at the latitude of

$10135^{\circ} \mathrm{N} / \mathrm{S}$ is $68 \%$ shorter than at the equator. The peak calendar months of

102 fruiting are variable among different regions of the tropics, but fruiting tends to

103 occur during a more limited time of the year (autumn) in temperate regions.

104 Third, the proportion of animal-dispersed fleshy fruits is larger in

105 tropical than in temperate forests, although there has been no systematic review.

106 For example, on the one hand, in tropical forests, fleshy-fruited species

107 constitute $76-100 \%$ in Peru, $65 \%$ in Costa Rica, $78-94 \%$ in other Neotropical

108 sites and $>67 \%$ in Malaya (Willson et al. 1989). On the other hand, in 127

109 temperate forests of Japan, the proportion of fleshy-fruited species is $58 \%$ (Otani

110 2005). There have been a few studies on the proportion of fleshy fruits in the

111 actual biomass. In Kakachi, southern India, fleshy-fruits account for $36 \%$ of the

112 wet weight of fruit fall (Ganesh and Davidar 1999). In Lopé Reserve, Gabon,

113 fleshy fruits account for $54 \%$ of the total number of fallen fruits (White 1994).

114 By contrast with these tropical forests, in five warm- and cool-temperate forests

115 in Yakushima, Japan, fleshy fruits constitute only 3-37\% of the fruit fall (Hanya

116 and Aiba 2010a). In these temperate forests, there is a common tendency for a

117 few (often only one) particular non-fleshy species, usually large-sized acorns of

118 Fagaceae or cones of conifers, to account for most (42-59\%) of the fruit fall.

119 Although data are available from only a few sites, the same tendency is likely to

120 occur in other temperate forests because these species often become dominant

121 in temperate forests (Hendrick 2001).

In summary, these previous studies found that in temperate forests, fruit

123 availability is lower with respect to biomass and species composition and that 
124 fruiting seasonality is stronger but predictable with respect to timing than in

125 tropical forests. However, we cannot yet draw the whole picture of temperate

126 and tropical forests as primate habitats. In addition to fruits and seeds, leaves

127 provide another major component of primate food, and their availability varies

128 across seasons (Clutton-Brock 1977). However, the global pattern in the

129 variability of young leaf availability has not yet been clarified, as in the case of

130 fruit availability. In addition, although the fruit availability pattern in a single year

131 has largely been clarified, supra-annual patterns remain unknown. This is

132 potentially an important factor in primate feeding ecology (Tsuji and Takatsuki

133 2012).

In this paper, we aim to clarify the differences between temperate and

135 tropical forests as food environments for primates, in particular the seasonality of

136 fruiting and flushing, which provide the two most important food resources for

137 primates. As a target region, we examine data from Asia. This is where

138 primates are distributed most extensively in the temperate region. In addition,

139 our data collection (see Method) revealed that virtually no data are available for

140 temperate forests in other primate habitats, such as North and South Africa,

141 Northern Argentina, and Southern Madagascar. Specifically, we compare two

142 aspects of supra-annual patterns of fruiting: the intensity of annual periodicity

143 and inter-annual variations. As for flushing, we examine data on the time of the

144 flushing peak and the duration of the flushing season. Finally, we discuss the

145 implications of the differences in habitat, revealed by this and previous studies,

146 on primate feeding ecology. 
149 In this paper, we regard the border between temperate and tropical Asia as the 150 Tropic of Cancer $\left(23^{\circ} 26^{\prime} \mathrm{N}\right)$.

$151 \quad$ Data on community-wide fruiting and flushing phenology for

152 comparative analysis were obtained from the literature (Supplementary Material).

153 We used the ISI Web of Science (http://apps.isiknowledge.com/). For fruiting,

154 on December 22, 2011, we conducted our search by inputting the keywords 'fruit

155 AND phenology'. As for flushing, on December 19, 2011, we used the

156 keywords 'phenology AND flushing OR young leaf'. These searches produced

1571713 and 477 results, respectively. We also examined 348 papers on primate

158 feeding ecology. We read the abstracts of these papers and selected those

159 papers that referred to the community-wide phenology in Asian primate habitat

160 countries. If we judged that the study did not include systematic sampling or

161 the sampling interval was more than a month, we did not use the paper. As for

162 fruiting, we were interested in the supra-annual patterns, so we included only the

163 studies that covered at least two consecutive years. For flushing, we included

164 all of the papers whose studies lasted at least one year in order to increase the

165 sample size. In addition, in the analysis of inter-annual variation of fruiting, we

166 also included data of 10 sites that did not include monthly values of fruit fall but

167 did report the annual values for multiple study years. As for fruiting, data were

168 available from 24 sites with latitudes of $0^{\circ} \mathrm{S}-42^{\circ} \mathrm{N}$. Since some authors reported 169 phenology data using multiple indices, we analyzed 31 datasets in total. As for

170 flushing, we examined data from 17 sites (17 datasets), with latitudes of

$1713^{\circ} \mathrm{N}-42^{\circ} \mathrm{N}$. The number of sites was 9 in tropical and 15 in temperate forests for

172 fruiting and 8 and 9 for flushing (see Supplementary Materials for details about

173 the study sites). 
175 number of species, (2) number of plant individuals (whether climbers are

176 included or not depends on the study), (3) sum of basal area of trees, and (4)

177 weight of litter fall. We conducted analysis separately for these four types

178 except for the analysis of flushing peak because peak is expected to coincide

179 with whatever index is used (Hanya and Aiba 2011). Because of data

180 availability, only (1), (2) and (4) were analyzed for fruiting and only (1), (2) and

181 (3) were used in the analysis of flushing. Because data of (3) for flushing were 182 available for tropical regions only and that of (1) were for temperate regions only, 183 these data were used only to compare flushing peak with latitude. These different indices are expected to correlate with each other, and 185 thus any difference between the regions in at least one of the indices suggests 186 there is a difference in food availability in a broad sense. However, these 187 indices represent different aspects of food availability, and thus the discrepancy 188 in the results among indices may explain the situation that the primates are 189 facing. The number of fruiting/flushing species indicates the diversity available 190 to primates for a given period. The number of fruiting/flushing plant individuals 191 represents the number of patches, thus it is likely to correlate with the searching 192 cost for primates (Hanya 2009). The sum of basal areas or the weight of litter 193 would be more strongly correlated with the actual food biomass than with other 194 indices. Therefore, we treat all of the indices separately in the analysis.

195 However, caution needs to be taken in the interpretation of the results because 196 the data sources are different for different indices.

197 For each study site, we collected the following information: (1) latitude, 198 (2) longitude, (3) annual average temperature, and (4) annual precipitation. 
199 The direct effect of longitude on phenology was not assessed but used only to 200 calculate the inter-site distance in order to correct the spatial autocorrelation.

201 We used the absolute values of latitude in the analysis of its effect on phenology;

202 therefore, northern and southern hemispheres were treated equally. Data on

203 annual average temperature and annual precipitation were derived from original 204 publications whenever possible. When not available, data from the nearest 205 meteorological station were used, using the database 'World Climate' 206 http://www.climate-charts.com/. In cases where the altitude of the 207 meteorological station differed from the study site by more than $200 \mathrm{~m}$, we 208 corrected the temperature value by assuming that the temperature lapse rate is $2090.6^{\circ} \mathrm{C} / 100 \mathrm{~m}$ (Martyn 1992). This database is reliable because the temperature 210 and precipitation values from the original literature significantly positively 211 correlated with the values obtained through this database (temperature: $r=0.93$, $212 p=2.59 * 10^{-9}$; precipitation: $\left.r=0.84, p=1.66^{*} 10^{-6}\right)$. We defined the index on phenology as follows:

214 Annual periodicity of fruiting: In order to control the length of the study period, we 215 used the data of the first 24 months only. We performed a series of (12) 216 generalized linear models (GLM) using cosine wave functions (Anderson et al. 2172005 ) with periodicities of 12 months having maximum values in either of the 12 218 months. We used the $\mathrm{R}^{2}$ value of the best-fit model (with lowest Akaike 219 Information Criterion AIC) as an index of the degree of annual periodicity 220 (Hanya and Aiba 2011).

221 Inter-annual variation of fruiting: We examined the data of the first 24 months 222 only. We quantified its intensity as (sum of the 12 months, year of larger 223 value)/(sum of the 12 months, year of the smaller value). 
224 Peak of flushing: Following Ting et al. (2008), we defined the peak as the circular 225 average of the value of the first 12 months. The arithmetic average of February 226 (month 2) and December (month 12) is July (month 7), but in reality, it should be 227 January. Therefore, we need to apply 'circular' statistics when examining 228 annual cycles. Each month $i$ (=Jan, Feb, ...) was converted to an angle series 229 $a_{i}\left(=15^{\circ}, 45^{\circ}, \ldots\right)$. Using the corresponding number of flushing index (e.g.

230 number of species), $f_{i}$ (normalized by dividing by average), the mean angle $231\left(0^{\circ}-360^{\circ}\right.$, roughly equivalent to the day of the year) of flushing, $\mu_{f}$, was calculated 232 as follows:

233

$$
\mu_{f}= \begin{cases}\text { If } C>0, S \geq 0 \quad \mu_{f}=\arctan (S / C) \\ \text { If } C=0, S>0 \quad \pi / 2 \\ \text { If } C<0 & \arctan (S / C)+\pi \\ \text { If } C \geq 0, S<0 & \arctan (S / C)+2 \pi \\ \text { Undefined if } C=0, S=0\end{cases}
$$

238 whereas

239

$C=\frac{\sum_{i=1}^{12} f_{i} \cos a_{i}}{12}$

$240 \quad S=\frac{\sum_{i=1}^{12} f_{i} \sin a_{i}}{12}$

241 Flushing duration: Following Ting et al. (2008), we defined the duration as the 242 circular standard deviation of the value of the first 12 months. Circular standard 243 deviation $s$ was calculated as:

$244 s=\frac{180 \sqrt{-2 \ln r}}{\pi}$ 
$246 \quad r=1-\sqrt{C^{2}+S^{2}}$

$247 \quad r$ is the relative length of the mean vector, ranging from 0 to 1.

Following a similar analysis of fruiting (Ting et al. 2008), we examined

249 the peak of flushing only graphically because the obtained results are circular

250 values and thus not suitable for conventional statistics, such as the t-test. For

251 this parameter, we are interested only in whether the peak month is

252 concentrated in a particular season. As for the other parameters of phenology,

253 we examined the effects of environmental factors in three ways: (1) a simple

254 t-test between the temperate and tropical Asia, (2) generalized least squares

255 (GLS) regression on the effect of location (absolute latitude), and (3) GLS

256 regression on the effect of climate (annual average temperature and

257 precipitation). We separated location and climate models because these two

258 factors affect phenology at different causal levels: In principle, location

259 determines climate and climate in turn determines phenology. GLS models are

260 similar to general linear models (GLM), except that their estimates of standard

261 errors and type-I errors are more realistic in the presence of spatially correlated

262 residuals (Dormann et al. 2007). GLS models also prevent clusters of sites

263 from exerting undue (pseudo-replicated) influence on estimates of beta

264 coefficients, which may be an important consideration if study sites are not

265 uniformly distributed in space (Ting et al. 2008). Among the three common

266 variogram models, we used 'Gaussian' because it always fit the data most. For

267 both location and climate models, we ran the full models and examined the effect

268 of the independent variables. All of the statistical analyses were conducted

269 using R 2.13. 2. (C 2011 The R Foundation for Statistical Computing), and GLS

270 models were fit using the 'gls' command of the 'nlme' package. 
272 Results

$273 \quad$ Fruiting

274 Annual periodicity in fruiting was larger in temperate than in tropical forests.

275 The difference was significant when assessed by the number of species $(t=2.71$, $276 \mathrm{p}=0.030)$ and by the number of plant individuals $(t=2.83, p=0.025)$, but not when 277 assessed by fruit litter ( $t=0.13, p=0.90$; Fig. 1$)$. According to the GLS location 278 models, the effect of absolute latitude was significant when assessed by the 279 number of species and plant individuals, but was not significant when assessed 280 by fruit litter (Table 1abc). Climate models indicated that temperature significantly negatively affected the annual periodicity when assessed by the number of plant individuals or fruit litter but not when assessed by the number of species (Table 1def). There was also a tendency for annual periodicity to be higher in drier areas when assessed by the number of plant individuals (Table 1e) but not when assessed by other indices (Table 1df). There was no significant difference in inter-annual variation of fruiting between temperate and tropical forests when assessed by the number of species $(t=1.92, p=0.096)$ or plant individuals $(t=0.98, p=0.36)$ or by fruit litter $(t=0.48, p=0.64)$ (Fig. 2). None of the GLS models included absolute latitude as a significant variable (Table 2abc). Among the climate models, the only significant independent factor was precipitation (positive) when assessed by the 292 number of plant individuals (Table 2def). Inter-annual variation in some 293 temperate forests (Uji and Chichibu in Japan) was quite large (779 and 2608, 294 respectively). Fruit fall in these forests was dominated by acorns (Quercus or 295 Fagus). 
297 Flushing

298 The flushing peak in tropical Asia occurred in various periods of a year, but in

299 temperate Asia, the peak occurred only in spring and early summer (April 300 through June, Fig. 3).

Length of flushing season was longer in tropical than in temperate Asia

302 when assessed by the number of plant individuals ( $t=2.59, p=0.032)$ (Fig. 4).

303 GLS location also included absolute latitude as a significant factor (Table 3a).

304 The circular standard deviation of flushing season in tropical Asia (mean+SD:

$30565+51$ when assessed by the number of plant individuals) was 2.7 times longer

306 than in temperate Asia $(24.5+4.4)$. Data with the number of species was

307 available only for temperate Asia, but it was also very short $(18.7+6.4)$. None of

308 the factor was significant in the climate model (Table 3b).

309

310 Discussion

311 Overall, the difference between temperate and tropical Asia was made clear

312 both in the t-test and the GLS analyses. Since the vegetation in the Japanese

313 archipelago is diverse and shares many similarities with continental temperate

314 East Asia (Hendrick 2001; Takyu et al. 2005), we believe that Japan can be used

315 as a representative in East Asian temperate primate habitat. So far, data from

316 other temperate regions are deficient to examine the validity of our conclusion,

317 and our conclusions should be reexamined in the future when data are

318 accumulated for other temperate regions.

320 Fruit availability 
321 Our comparative study revealed that fruiting is more annually periodic in

322 temperate than in tropical Asia but that there is no consistent difference in 323 inter-annual variations.

There are two aspects of predictability in the timing of fruiting. One is

325

326

327

328

329

330

331

332

333

334

335

336

337

338

339

340

341 the inter-site predictability shown by Ting et al. (2008). They indicated that the timing of fruiting peak is more or less the same period of a year (autumn) in any temperate forest. The other aspect is inter-annual predictability, or annual periodicity, shown by our analysis. We have shown that the fruiting phenology in one year is similar to that in another year in the same area. However, this is true only at the plant species or individual level, not at the level of fruit biomass. Hanya and Aiba (2011) pointed out that when assessed by the fruit biomass, community-level annual periodicity can be disturbed by the heavy fruiting of a few species that bear fruits out of the fruiting peak. Therefore, primates in temperate forests are likely to experience the same degree of species diversity and patch density for fruit resources in the same calendar month of different years. However, the season when fruits are most abundant (in terms of biomass) may be different over years, as in tropical forests. Analyses of climate models indicated that not only colder habitats but also drier habitats tended to show an annual periodic pattern of fruiting. In these areas, plant fruiting behavior is constrained by seasonal climatic stress, such as drought or winter coldness, which comes at a predictable period each year. However, again, with regard to fruit biomass, no such tendency was found.

We could not find any consistent differences in the inter-annual variations between the temperate and tropical Asia. It is already known that inter-annual variations in fruiting can be large in lowland dipterocarp forests in 
346 Southeast Asia, where mast fruiting occurs (Sakai 2002); however, the degree of

347 variability seems even larger in some temperate forests when assessed by fruit

348 litter. Since we could not detect any such huge inter-annual variations when

349 assessed by the number of species or plant individuals, this large variation is

350 caused mainly by the heavy fruiting of individual plants, not by the within- or

351 between-species synchronization of fruiting. Four temperate sites exhibited

352 larger inter-annual variations than the maximum value in tropical forests (14.1 in

353 Danum Valley, Borneo). In all four of these forests, almost $100 \%$ of the fruit fall

354 was occupied by acorns, such as Quercus and Fagus. Masting of acorns

355 seems to occur at a much larger scale than any other plants, and thus the

356 dominance of Fagaceae in many temperate forests seems to result in extreme

357 community-level inter-annual variability in some temperate forests. The

358 extreme variability in temperate regions in our dataset probably arose because

359 we assessed inter-annual variability using data of only two years. In our

360 method, intensified inter-annual variation would be detected only when either

361 one of the two years included mast years. In the future, we need to assess

362 inter-annual variability with phenology data of many years, which are currently

363 not available. We found a significant effect of precipitation on inter-annual

364 variability when assessed by the number of plant individuals, but we are not

365 aware of any biological explanation for it.

367 Young leaf availability

368 The characteristics of flushing phenology in temperate and tropical Asia are

369 summarized as follows: 1) peak timing (spring or early summer) is similar among

370 different sites in temperate regions but that in the tropics is variable, and 2) the 
371 duration of young leaf availability is shorter in temperate than in tropical regions.

372 The duration of flushing season in temperate Asia was only $17-28 \%$ of

373 that in tropical Asia, and the difference between the two regions was even

374 greater than in the case of fruiting (68\%) (Ting et al. 2008). Since the circular

375 standard deviation of fruiting season at $30^{\circ} \mathrm{N} / \mathrm{S}$ is 80 (Ting et al. 2008), the small

376 value of flushing in temperate forest (18.7-24.5) indicates that, in temperate

377 forests, young leaf is a temporarily more limited resource than fruit. In fact, in

378 many temperate forests analyzed in this study, flushing was observed for only 2

379 months in a year.

380 The flushing peak was observed only during a limited period of a year

381 in temperate forests. At $>20^{\circ} \mathrm{N}$ in the Asia, the flushing peak occurred only in

382 April, May and June. Fruiting also tends to have a peak in a limited season

383 (autumn) (Ting et al. 2008); however, the actual peak month was more variable

384 than in the case of flushing: at $>30^{\circ} \mathrm{N}$, fruiting peak occurred in September

385 through January and, in one case, in June (Ting et al. 2008).

The highly predictable peak months and the short duration of flushing

387 season is probably the result of cold stress in winter, which is shared by all of the

388 temperate plants. Cold stress should inhibit plant photosynthetic activity, and

389 once plants are released from this stress after winter, it is important for them to

390 flush young leaves immediately in order to increase net annual productivity. It

391 may be possible for even tropical plants to increase photosynthetic activity by

392 synchronizing flushing with abiotic climatic events, such as solar maxima (van

393 Schaik et al. 1993). However, in our current data set, there was no

394 circular-circular correlation between the time of solar maxima and the flushing

395 peak $(r=0.12, p=0.54)$. Thus, the selection pressure to make tropical plants 
396 synchronize flushing to solar maxima is not so large as the cold stress in

397 temperate regions.

398

399 Implications for primate ecology

400 The temperate region harbors approximately 20 genera of primates, including

401 Microcebus, Cheirogaleus, Hapalemur, Lemur, Eulemur, Lepilemur, Avahi,

402 Propithecus, Nycticebus, Leontopithecus, Alouatta, Aotus, Brachyteles, Cebus,

403 Chlorocebus, Cercopithecus, Papio, Macaca, Trachypithecus, Presbytis,

404 Semnopithecus, Rhinopithecus, and Hylobates living in East Asia, North and

405 South Africa, South America and Madagascar (Fleagle 1999). Our analyses on

406 habitat included only Asia, thus our discussion on implications for primate

407 ecology is primarily applicable to Asian primates. However, it may lead the way

408 for future investigations into adaptations of temperate primates of various taxa

409 living in other regions.

410 First, we found that fruit and young leaf availability is smaller than in

411 tropical forest in terms of biomass (smaller fruit fall), seasonality (shorter fruiting

412 and flushing season), and species composition (smaller proportion of fleshy

413 fruits). Therefore, it is predicted that temperate primates need to survive a long

414 period of scarcity of young leaves and fruits. In accordance with this the

415 prediction, both Hanya (2004) and Grueter et al. (2009), who proposed fallback

416 strategies of Japanese macaques and Chinese snub-nosed monkeys,

417 respectively, pointed out that during the lean period (winter), primates fall back to

418 lower-quality foods than fruits and young leaves, such as mature leaves, lichens,

419 bark and buds. We also found that the flushing season in temperate forest

$420(17-28 \%$ of that in tropical forest) was quite limited even compared with the 
421 fruiting season (68\%). Fruits and seeds sometimes become the main food

422 even for temperate primates (Hanya et al. 2011a), but young leaf is never

423 reported to be so (Grueter et al. 2009). When fruit availability is low, young leaf

424 is often an option as a fallback food for tropical primates (Kanamori et al. 2010;

425 Hanya and Bernard 2012), but it is impossible for temperate primates to rely on

426 young leaves, in particular in winter, when fruit scarcity is likely to occur in

427 temperate forests.

Another finding of our analysis was the high predictability of fruiting phenology in temperate forest. Concerning this, Hanya (2004) pointed out the effectiveness of fat accumulation as another fallback strategy for temperate primates. Accumulation of fat during the fruit-abundant period and consumption during the subsequent fruit-scarce period can be an effective strategy if the timing of the end of the lean season is predictable. If not, animals cannot predict the amount of fat necessary to survive the lean period, and thus heavy reliance on accumulated fat is a risky strategy. Fat accumulation has been widely reported among temperate macaques (Wada 1975; Zhao 1994; Muroyama et al. 2006) and other endotherms (Pond 1978). However, there 438 has been no reported evidence for other temperate primates, such as colobines. 439 Temperate colobus monkeys, as well as temperate macaques, increase fruit- or 440 seed-eating in autumn (Guo et al. 2007; Sayers and Norconk 2008; Grueter et al. 441 2009). It is not clear whether the nutritional condition of colobus monkeys 442 actually improves so much as to accumulate fat by the consumption of fleshy 443 fruits. Consumption of a large amount of carbohydrates or fleshy fruits abruptly 444 changes the $\mathrm{pH}$ of the forestomach of colobines, which is believed to cause fatal 445 affliction (acidosis) (Kay and Davies 1994). However, fleshy ripe fruit is known 
446 to become a main food, at least in a particular season for two species of

447 colobines (Sayers and Norconk 2008; Grueter et al. 2009). Future studies on

448 the digestive physiology of colobines, in particular the digestion of fleshy fruits,

449 and their ability of fat accumulation are necessary in order to understand their

450 fallback strategy in temperate regions.

451 In addition to feeding strategy, the strong seasonality and high

452 predictability in food availability in temperate forests may also affect other

453 aspects of primate ecology. Temperate primates may exhibit seasonal

454 breeding (Valdespino 2007), larger home range size (Li et al. 2000; Hanya et al.

455 2006; Grueter et al. 2008), lower species diversity (Eeley and Lawes 1999) and

456 lower biomass (Hanya et al. 2011b). Systematic comparisons are necessary to

457 confirm whether primates show dichotomy between temperate and tropical

458 regions with respect to these characteristics and how it relates to the

459 characteristics of temperate forests revealed by this study.

460

461 In conclusion, we have shown that in temperate forests, fruit and young leaf

462 availability is smaller than in tropical forest in terms of biomass (smaller fruit fall),

463 seasonality (shorter duration fruiting and flushing season), and species

464 composition (smaller proportion of fleshy fruits). Both fruiting and flushing tend

465 to occur in a limited period of a year, that is, autumn and spring, respectively.

466 Predictability of fruiting season, both in terms of space and over time, was higher

467 in temperate than in tropical forest. In response to this variation, we predict that

468 temperate primates rely on more low-quality food, such as mature leaves,

469 lichens, bark and buds. High predictability of fruiting seasonality enables the

470 temperate primates to rely on fat which was accumulated during the 
471 fruit-abundant period to survive the fruit-scarce winter.

472

473 Acknowledgements

474 We would like to thank our friends and colleagues who helped our fieldwork in 475 Japan, China and Malaysia, which formed the basis of this paper. We thank 476 Kevin Burns for his advice on circular statistics. This study was financed by the 477 MEXT Grant-in-Aid (No. 20770195, No. 22687002 and No. 23657018) to GH, 478 the 21st Century COE Program (A14), Global COE Program "Formation of a 479 Strategic Base for Biodiversity and Evolutionary Research: from Genome to 480 Ecosystem" and the Kyoto University Foundation.

481

482 References

483 Anderson DP, Nordheim EV, Moermond TC, Gone Bi ZB, Boesch C (2005)

484 Factors influencing tree phenology in Taï National Park, Côte d'Ivoire.

$485 \quad$ Biotropica 37: 631-640

486 Badgley C, Fox DL (2000) Ecological biogeography of North American

487 mammals: species density and ecological structure in relation to

488 environmental gradients. J Biogeogr 27: 1437-1467

489 Clutton-Brock TH (1977) Primate Ecology: Studies of Feeding and Ranging 490 Behaviour in Lemurs, Monkeys and Apes. Academic Press, Brighton 491 Dormann CF, McPherson JM, Araujo MB, Bivand R, Bolliger J, Carl G, Davies 492 RG, Hirzel A, Jetz W, Kissling WD, Kuhn I, Ohlemuller R, Peres-Neto PR, 493 Reineking B, Schroder B, Schurr FM, Wilson R (2007) Methods to account 494 for spatial autocorrelation in the analysis of species distributional data: a 495 review. Ecography 30: 609-628 
496 Eeley H, Lawes MJ (1999) Large-scale patterns of species richness and species

497 range size in anthropoid primates. In: Fleagle J, Janson C, Reed K (eds.)

498 Primate Communities. Cambridge Univ Press, Cambridge, pp 191-219

499 Fleagle JG (1999) Primate Adaptation and Evolution. Second Edition.

$500 \quad$ Academic Press, London

501 Ganesh T, Davidar P (1999) Fruit biomass and relative abundance of frugivores

502 in a rain forest of southern Western Ghats, India. J Trop Ecol 15: 399-413

503 Grueter CC, Li DY, van Schaik CP, Ren BP, Long YC, Wei FW (2008) Ranging of

504 Rhinopithecus bieti in the Samage Forest, China. I. Characteristics of Range

$505 \quad$ Use. Int J Primatol 29: 1121-1145

506 Grueter CC, Li DY, Ren BP, Wei FW, Xiang ZF, van Schaik CP (2009) Fallback

507 foods of temperate-living primates: a case study on snub-nosed monkeys.

$508 \quad$ Am J Phys Anthropol 140: 700-715

509 Guo SG, Li BG, Watanabe K (2007) Diet and activity budget of Rhinopithecus

510 roxellana in the Qinling Mountains, China. Primates 48: 268-276

511 Hanya G (2004) Diet of a Japanese macaque troop in the coniferous forest of

$512 \quad$ Yakushima. Int J Primatol 25: 55-71

513 Hanya G, Kiyono M, Yamada A, Suzuki K, Furukawa M, Yoshida Y, Chijiiwa A

514 (2006) Not only annual food abundance but also fallback food quality

515 determines the Japanese macaque density: evidence from seasonal

$516 \quad$ variations in home range size. Primates 47: 275-278

517 Hanya G, Kiyono M, Hayaishi S (2007) Behavioral thermoregulation of wild

518 Japanese macaques: Comparisons between two subpopulations. Am J

$519 \quad$ Primatol 69: 802-815

520 Hanya G (2009) Effects of food type and number of feeding sites in a tree on 
aggression during feeding in wild Macaca fuscata. Int J Primatol 30: 569-581

522 Hanya G, Aiba S (2010a) Fruit fall in five warm- and cool-temperate forests in

523 Yakushima, Japan. Forestry Studies in China 12: 184-192

524 Hanya G, Aiba S (2010b) Fruit fall in tropical and temperate forests: implications 525 for frugivore diversity. Ecol Res 25: 1081-1090

526 Hanya G, Aiba S (2011) Annual periodicity in fruiting in temperate forests in

527 Yakushima, Japan. Forestry Studies in China 13: 112-122

528 Hanya G, Menard N, Qarro M, Ibn Tattou M, Fuse M, Vallet D, Yamada A, Go M, 529 Takafumi H, Tsujino R, Agetsuma N, Wada K (2011a) Dietary adaptations of 530 temperate primates: comparisons of Japanese and Barbary macaques. Primates 52: 187-198

532 Hanya G, Stevenson P, van Noordwijk M, Wong ST, Kanamori T, Kuze N, Aiba S, 533 Chapman CA, van Schaik C (2011b) Seasonality in fruit availability affects 534 frugivorous primate biomass and species richness. Ecography 34:

$535 \quad 1009-1017$

536 Hanya G, Bernard H (2012) Fallback foods of red leaf monkey (Presbytis rubicunda) in Danum Valley, Borneo. Int J Primatol 33: 322-337

538 Hendrick RL (2001) Forest types and classification. In: Evans J (ed. The Forest

539 Handbook volume 1: An Overview of Forest Science. Springer, Oxford, pp $540 \quad 23-64$

541 Hillebrand $\mathrm{H}$ (2004) On the generality of the latitudinal diversity gradient. Am Nat $542 \quad 163: 192-211$

543 Hohmann G, Robbins MM, Boesch C (2006) Feeding Ecology in Apes and Other $544 \quad$ Primates. Cambridge University Press, Cambridge

545 Iwamoto T, Dunbar RIM (1983) Thermoregulation, habitat quality and the 
behavioral ecology of gelada baboons. Journal of Animal Ecology 52: 357-366

548 Kanamori T, Kuze N, Bernard H, Malim TP, Kohshima S (2010) Feeding ecology

549 of Bornean orangutans (Pongo pygmaeus morio) in Danum Valley, Sabah,

550 Malaysia: A 3-year record including two mast fruitings. Am J Primatol 72:

$551 \quad 820-840$

552 Kay RNB, Davies AG (1994) Digestive physiology. In: Davies AG, Oates JF

553 (eds.) Colobine Monkeys: Their Ecology, Behaviour and Evolution.

554 Cambridge University Press, Cambridge, pp 229-249

555 Lechowicz MJ (1995) Seasonality of flowering and fruiting in temperate forest

$556 \quad$ trees. Can J Bot-Rev Can Bot 73: 175-182

557 Li BG, Chen C, Ji WH, Ren BP (2000) Seasonal home range changes of the

558 Sichuan snub-nosed monkey (Rhinopithecus roxellana) in the Qinling

559 mountains of China. Folia Primatol 71: 375-386

560 Martyn D (1992) Climates of the World. Elsevier, Amsterdam

561 Muroyama $\mathrm{Y}$, Kanamori H, Kitahara E (2006) Seasonal variation and sex

562 differences in the nutritional status in two local populations of wild Japanese

563 macaques. Primates 47: 355-364

564 Nakagawa N, Iwamoto T, Yokota N, Soumah AG (1996) Inter-regional and

565 inter-seasonal variations of food quality in Japanese macaques: Constraints

566 of digestive volume and feeding time. In: Fa JE, Lindburg DG (eds.) Evolution

567 and Ecology of Macaque Societies. Cambridge Univ Press, New York, pp

$568 \quad 207-234$

569 Otani T (2005) Characteristics of middle-size mammals as a seed disperser of 570 fleshy-fruited plants (in Japanese). Nagoya Univ For Sci 24: 7-43 
571 Pond CM (1978) Morphological aspects and ecological and mechanical

572 consequences of fat deposition in wild vertebrates. Annu Rev Ecol Syst 9:

$573 \quad 519-570$

574 Sakai S (2002) General flowering in lowland mixed dipterocarp forests of

$575 \quad$ South-east Asia. Biol J Linnean Soc 75: 233-247

576 Sayers K, Norconk MA (2008) Himalayan Semnopithecus entellus at Langtang

577 National Park, Nepal: Diet, activity patterns, and resources. Int J Primatol 29:

$578 \quad 509-530$

579 Stevens RD, Willig MR (2002) Geographical ecology at the community level:

580 Perspectives on the diversity of new world bats. Ecology 83: 545-560

581 Takasaki H (1981) Troop size, habitat quality, and home range area in Japanese

582 macaques. Behav Ecol Sociobiol 9: 277-281

583 Takyu M, Kubota Y, Aiba S, Seino T, Nishimura T (2005) Pattern of changes in

584 species diversity, structure and dynamics of forest ecosystems along

$585 \quad$ latitudinal gradients in East Asia. Ecol Res 20: 287-296

586 Ting S, Hartley S, Burns KC (2008) Global patterns in fruiting seasons. Glob

$587 \quad$ Ecol Biogeogr 17: 648-657

588 Tsuji Y, Takatsuki S (2012) Interannual variation in nut abundance is related to

589 agonistic interactions of foraging female Japanese macaques (Macaca

$590 \quad$ fuscata). Int J Primatol 33: 489-512

591 Valdespino C (2007) Physiological constraints and latitudinal breeding season in

592 the Canidae. Physiol Biochem Zool 80: 580-591

593 van Schaik CP, Terborgh JW, Wright SJ (1993) The phenology of tropical forests:

594 adaptive significance and consequences for primary consumers. Annu Rev

$595 \quad$ Ecol System 24: 353-377 
596 van Schaik CP, Pfannes K (2005) Tropical climates and phenology: a primate

597 perspective. In: Brockman DK, van Schaik CP (eds.) Seasonality in Primates:

598 Studies of Living and Extinct Human and Non-Human Primates. Cambridge

$599 \quad$ University Press, Cambridge, pp 23-54

600 Wada K (1975) Ecology of wintering among Japanese monkeys in Shiga Heights

601 and its adaptive significance (in Japanese). Physiol Ecol Jpn 16: 9-14

602 White LJT (1994) Patterns of fruit fall phenology in the Lopé Reserve, Gabon. J

603 Trop Ecol 10: 289-312

604 Willson MF, Irvine AK, Walsh NG (1989) Vertebrate dispersal syndromes in

605 some Australian and New Zealand plant communities, with geographic

$606 \quad$ comparisons. Biotropica 21: 133-147

607 Zhao QK (1994) Seasonal changes in body weight of Macaca thibetana at

608 Mt-Emei, China. American Journal of Primatology 32: 223-226

609 Zhou YB, Newman C, Xu WT, Buesching CD, Zalewski A, Kaneko Y, Macdonald

610 DW, Xie ZQ (2011) Biogeographical variation in the diet of Holarctic martens

611 (genus Martes, Mammalia: Carnivora: Mustelidae): adaptive foraging in

612 generalists. J Biogeogr 38: 137-147

613

614

615 
616 Legends of figures

617 Fig. 1. Latitudinal variations in the degree of annual periodicity in fruiting. Index

618 of annual periodicity was the $\mathrm{R}^{2}$ value of the correlation model of monthly

619 phenology for two years on a cosine wave function having periodicity of 12

620 months. (a) When fruiting phenology is assessed by the number of species,

621 (b) number of plant individuals, and (c) fruit biomass.

622 Fig. 2. Latitudinal variations in the intensity of inter-annul variations of fruiting.

623 The intensity was calculated by dividing the sum of one year (the one with the

624 larger value) by the sum of the other year (smaller value). (a) When fruiting

625 phenology is assessed by the number of species, (b) number of plant

626 individuals, and (c) fruit biomass.

627 Fig. 3. Latitudinal variations in peak flushing months. Lines indicate the time of 628 solar maxima.

629 Fig. 4. Latitudinal variations in the length of flushing seasons, assessed by

630 circular standard deviation, when the flushing phenology is assessed by the 631 number of plant individuals. 
(a)
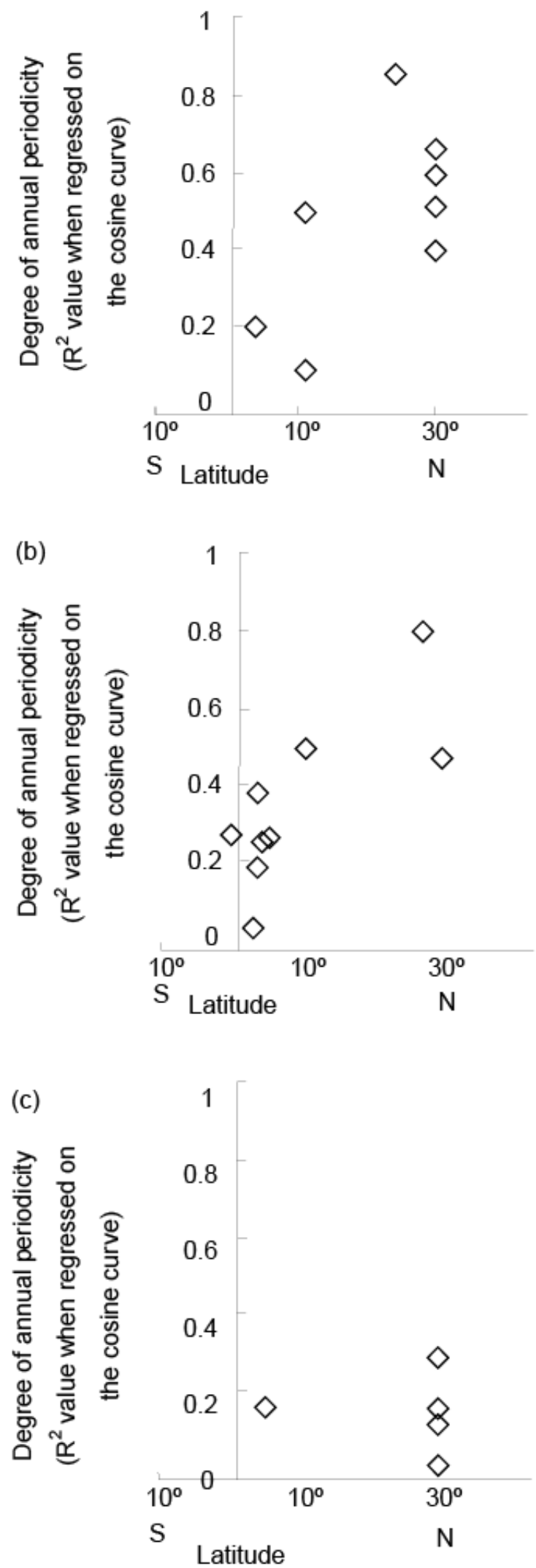

634 Fig. 1 

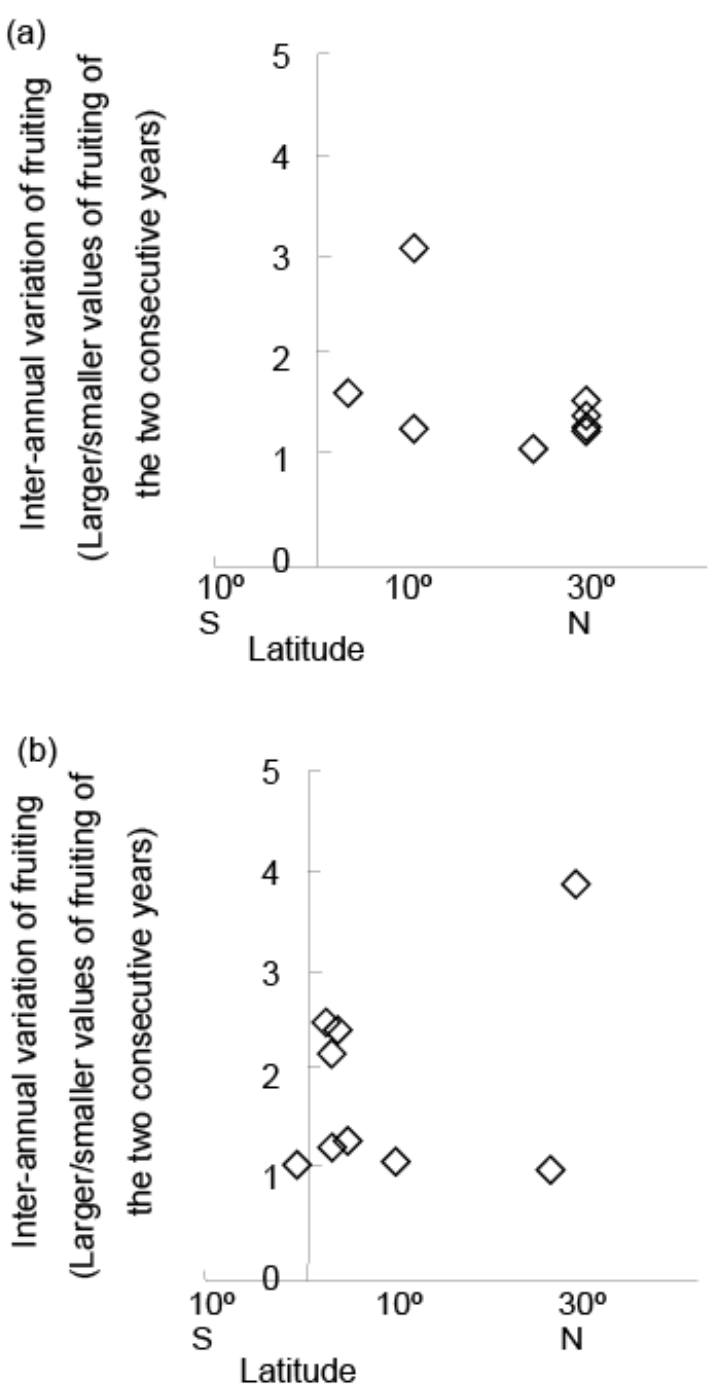

(c)

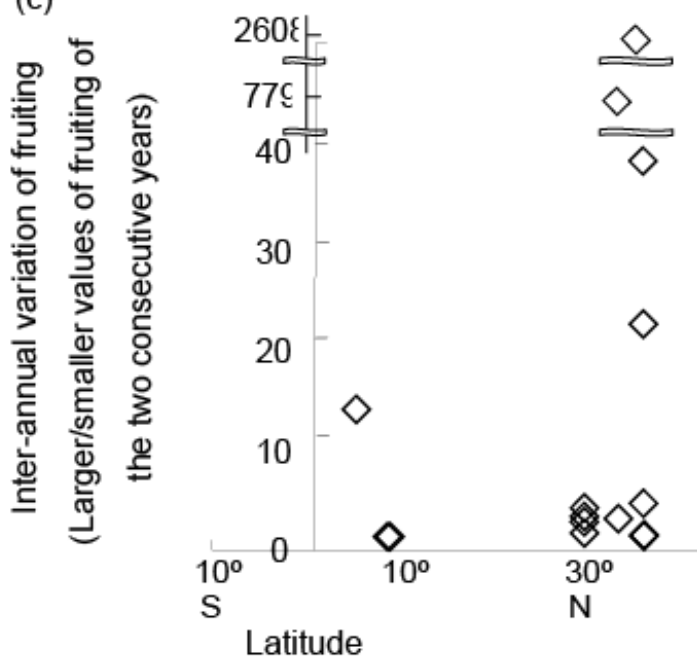

637 Fig. 2 




640 Fig. 3

641 
642

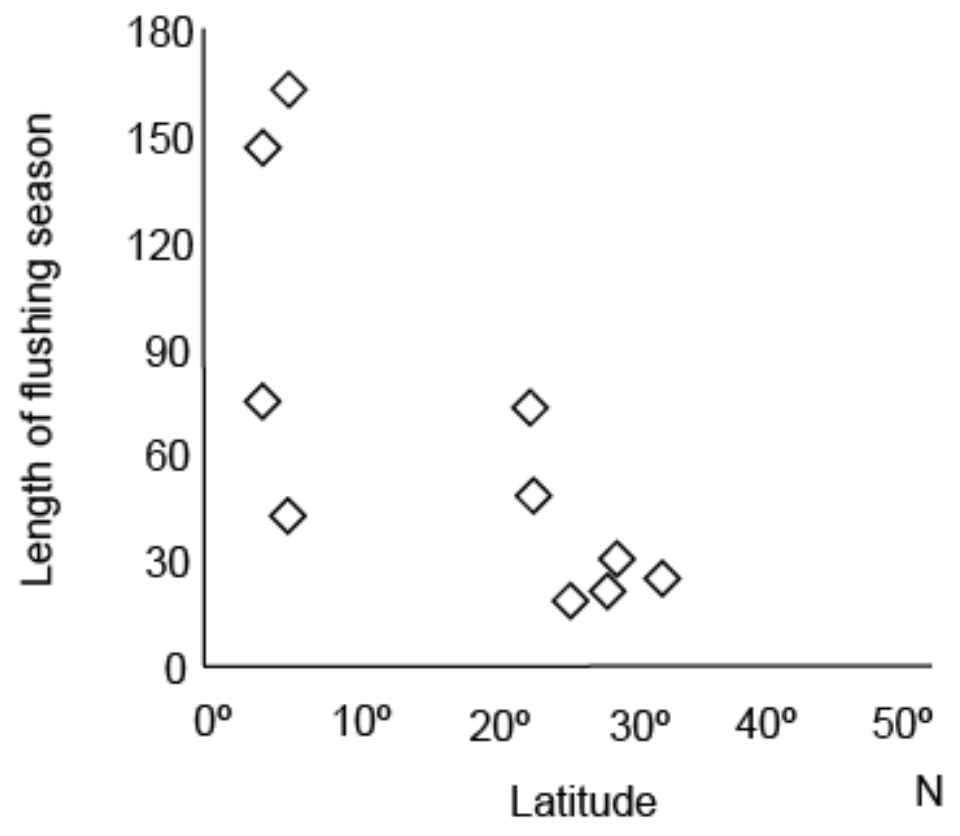

643 Fig. 4

644 
Table 1. GLS models on the effect of location or climate on annual periodicity in fruiting

a. Effect of location, assessed by the number of species

\begin{tabular}{lcccc}
\hline & Coefficient & SE & $t$ & $p$ \\
\hline Intercept) & 0.12 & 0.16 & 0.73 & 0.49 \\
Absolute latitude & 0.02 & 0.01 & 2.90 & 0.02 \\
\hline
\end{tabular}

b. Effect of location, assessed by the number of plant individuals

\begin{tabular}{lcccc}
\hline & Coefficient & SE & $t$ & $p$ \\
\hline (Intercept) & 0.22 & 0.08 & 2.88 & 0.02 \\
Absolute latitude & 0.01 & 0.00 & 2.96 & 0.02 \\
\hline
\end{tabular}

c. Effect of location, assessed by the fruit litter

\begin{tabular}{lcccc}
\hline & Coefficient & SE & $t$ & $p$ \\
\hline (Intercept) & 0.19 & 0.16 & 1.20 & 0.32 \\
Absolute latitude & 0.00 & 0.01 & -0.09 & 0.93 \\
\hline
\end{tabular}

d. Effect of climate, assessed by the number of species

\begin{tabular}{lcccc}
\hline & Coefficient & SE & $t$ & $p$ \\
\hline Intercept) & 1.37 & 0.57 & 2.41 & 0.05 \\
Rainfall & 0.00 & 0.00 & -1.24 & 0.26 \\
Temperature & -0.04 & 0.03 & -1.41 & 0.21 \\
\hline
\end{tabular}


e. Effect of climate, assessed by the number of plant individuals

\begin{tabular}{lcccc}
\hline & Coefficient & $\mathrm{SE}$ & $\mathrm{t}$ & $\mathrm{p}$ \\
\hline (Intercept) & 1.16 & 0.16 & 7.22 & 0.00 \\
Rainfall & 0.00 & 0.00 & -2.56 & 0.04 \\
Temperature & -0.03 & 0.01 & -4.63 & 0.004 \\
\hline
\end{tabular}

f. Effect of climate, assessed by the fruit litter

\begin{tabular}{lcccc}
\hline & Coefficient & $\mathrm{SE}$ & $\mathrm{t}$ & $\mathrm{p}$ \\
\hline (Intercept) & 0.78 & 0.22 & 3.59 & 0.07 \\
Rainfall & 0.00 & 0.00 & 0.56 & 0.63 \\
Temperature & -0.03 & 0.00 & -8.03 & 0.02 \\
\hline
\end{tabular}

646

647 
Table 2. GLS models on the effect of location or climate on intensity of inter-annual variations in fruiting

a. Effect of location, assessed by the number of species

\begin{tabular}{lcccc}
\hline & Coefficient & $\mathrm{SE}$ & $\mathrm{t}$ & $\mathrm{p}$ \\
\hline (Intercept) & 2.18 & 0.43 & 5.09 & 0.00 \\
Absolute latitude & -0.03 & 0.02 & -1.66 & 0.14 \\
\hline
\end{tabular}

b. Effect of location, assessed by the number of plant individuals

\begin{tabular}{lcccc} 
& Coefficie & SE & $t$ & $p$ \\
\hline (Intercept) & 1.45 & 0.51 & 2.88 & 0.02 \\
Absolute latitude & 0.03 & 0.03 & 1.07 & 0.32 \\
\hline
\end{tabular}

c. Effect of location, assessed by the fruit litter

\begin{tabular}{lcccc} 
& Coefficie & & & \\
& $\mathrm{nt}$ & $\mathrm{SE}$ & $\mathrm{t}$ & $\mathrm{p}$ \\
\hline (Intercept) & -291.15 & 779.31 & -0.3 & 0.71 \\
Absolute latitude & 30.88 & 26.74 & 1.15 & 0.27 \\
\hline
\end{tabular}

d. Effect of climate, assessed by the number of species

\begin{tabular}{llll}
\hline Coefficie & $S E$ & $t$ & $p$ \\
\hline
\end{tabular}




\begin{tabular}{|c|c|c|c|c|}
\hline (Intercept) & 1.05 & 1.36 & 0.77 & 0.47 \\
\hline Rainfall & 0.00 & 0.00 & -0.40 & 0.70 \\
\hline Temperature & 0.03 & 0.06 & 0.56 & 0.60 \\
\hline
\end{tabular}

e. Effect of climate, assessed by the number of plant individuals

\begin{tabular}{lcccc}
\hline & $\begin{array}{c}\text { Coefficie } \\
\text { nt }\end{array}$ & SE & $\mathrm{t}$ & $\mathrm{p}$ \\
\hline (Intercept) & 0.91 & 0.97 & 0.93 & 0.39 \\
Rainfall & 0.00 & 0.00 & 3.19 & 0.02 \\
Temperature & -0.03 & 0.03 & -0.91 & 0.40 \\
\hline
\end{tabular}

f. Effect of climate, assessed by the fruit litter

\begin{tabular}{lcccc}
\hline & $\begin{array}{c}\text { Coefficie } \\
\mathrm{nt}\end{array}$ & $\mathrm{SE}$ & $\mathrm{t}$ & $\mathrm{p}$ \\
\hline Intercept) & 476.96 & 371.4 & 1.28 & 0.22 \\
Rainfall & & 8 & & \\
Temperature & 0.00 & 0.01 & -0.06 & 0.95 \\
\hline
\end{tabular}


651

Table 3. GLS models on the effect of location or climate on the length of flushing season

a. Effect of location, assessed by the number of plant individuals

\begin{tabular}{lcccc}
\hline & Coefficient & SE & $t$ & $p$ \\
\hline Intercept) & 123.07 & 22.23 & 5.54 & 0.00 \\
Absolute latitude & -3.32 & 1.08 & -3.07 & 0.02 \\
\hline
\end{tabular}

b. Effect of climate, assessed by the number of plant individuals

\begin{tabular}{lcccc}
\hline & Coefficient & SE & $t$ & $p$ \\
\hline Intercept) & -19.83 & 48.19 & -0.41 & 0.69 \\
Rainfall & 0.02 & 0.02 & 0.66 & 0.53 \\
Temperature & 2.66 & 2.91 & 0.91 & 0.39 \\
\hline
\end{tabular}

